\author{
산림식생유형에 따른 조류 종다양성 분석* \\ 박인환 $^{1)} \cdot$ 김유훈 $^{2)} \cdot$ 조광진 $^{3)}$ \\ 1) 경북대학교 조경학과 · ${ }^{2)}$ 한국환경정책평가연구원 · ${ }^{3)}$ 국립농업과학원 기후변화생태과
}

\title{
Bird Species Diversity Analysis According to the Type of Forest Vegetation*
}

\author{
Park, In-Hwan ${ }^{1)} \cdot$ Kim, Yu-Hoon ${ }^{2)}$ and Cho, Kwang-Jin ${ }^{3)}$ \\ ${ }^{1)}$ Dept. of Landscape Architecture, Kyungpook National University, \\ ${ }^{2)}$ Korea Environment Institute, \\ ${ }^{3)}$ Climate Change and Agroecology Division, National Academy of Agricultural Science, RDA.
}

\begin{abstract}
For this paper, a study targeting 9 forest patches in Dangjin to suggest for the wild birds, was conducted. The correlation between the emergence of wild birds and the forest vegetation was analyzed, and the patterns of forest vegetation for the improvement of species diversity were suggested by classifying wild birds and foraging guild by the type of forest vegetation. As for the characteristics of the wild birds emerged, more species and bigger population appeared in the vegetation type of mixed stand forest where the natural deciduous broadleaf trees and evergreen needleleaf trees coexisted in the large scale vegetation area. Thus, it was known that the advent of summer migratory birds and resident birds were affected the most by forest patches and vegetation types. As for foraging guild, the larger the forest paches the more the species and the population of the wild birds inhabiting in shrubs and bushes.
\end{abstract}

* 본 논문은 2012년 한국조경학회 춘계학술대회의 산림식생유형에 따른 산림성조류의 종다양성 분석 논문을 일부 수정 보완한 것이며 2012학년도 경북대학교 학술연구비에 의하여 연구되었음.

First author : Park, In-Hwan, Dept. of Landscape Architecture, Kyungpook National University, Daegu 702-701, Republic of Korea,

Tel : +82-53-950-5775, E-mail : parkin@ knu.ac.kr

Corresponding author:Cho, Kwang-Jin, Climate Change and Agroecology Division, National Academy of Agricultural Science, RDA, Suwon 441-707, Korea,

Tel : +82-31-290-0234, E-mail : 4233125@hanmail.net

Received : 13 September, 2012. Revised : 24 December, 2012. Accepted : 24 December, 2012. 
Key Words : Bird species diversity, Forest vegetation, Vegetation area, Foraging guild, Wild birds.

\section{I. 서 론}

1960년대 이후 경제발전과 국토개발로 생물서 식지 파괴와 생물다양성의 극심한 쇠퇴를 초래하 여 산림 내 수종의 생육환경과 산림생태계의 종 다양성에 영향을 주었다.

급속한 근대화 및 산업화 과정에서 대규모의 농어촌 인구가 대도시로 집중되어 인구밀도가 높 아졌으며 무분별한 개발로 인해 녹지는 감소하고 단절되었다. 야생동물의 서식환경은 서식지의 크 기와 주 서식지와의 거리에 크게 영향을 받으며 단절된 녹지는 섬과 같은 소규모의 녹지로 세분 화되어 야생동물 서식지의 훼손으로 이어지고 결 국 생물종이 감소되는 결과를 가져왔다(Choi, 2004). 우리나라에 서식하는 생물종수는 10 만종 정도로 추정되며 국제적인 수준의 생물종 멸종화 율인 $0.5 \%$ 를 감안하면 국내에서는 매년 500 종의 생물이 사라지는 것으로 추산되고 있다. 이러한 생물다양성 감소의 주원인으로는 서식지의 혼란 과 감소, 과도한 밀렵행위, 불법채취 그리고 자생 지 훼손으로 인한 멸종 등을 꼽을 수 있다(Jang, 2008).

이렇게 악화되고 있는 자연환경의 질적 상태 및 변화 추세는 생물 지표종을 이용하여 알아 볼 수 있다. National Research Council(1986)에 의하 면 '생물체만이 어떤 유독 물질이 생체에 어떻게 작용하는지 말 할 수 있다' 고 하여 생물 지표종 사용을 적극 권장하기도 하였으며 이미 수중식물 과 연체동물들이 대기와 수질을 평가하는 성공적 인 지표로 사용되었다.

야생동물은 미적 가치, 휴양적 가치, 생태적 가 치, 교육·과학적 가치, 사업적 가치 등 다양한 가치를 지니고 있다. 이들은 문학, 예술의 대상으 로 인간에게 많은 휴양적인 가치를 제공하며 또 한 생태계의 구성원으로서 생태계의 안정성과 다
양성을 유지시켜 준다(Shaw, 1985).

한편, 생태계 먹이사슬의 상위단계이면서 도시 녹지에 서식하는 대표적인 야생동물인 야생조류 의 서식은 곤충 및 식물의 먹이자원이 풍요롭다 는 것을 의미하여 도시생태계의 질을 평가하는데 큰 척도가 될 수 있다. 특히 야생조류의 경우 외 부특징이 분명하여 관찰이 용이하고 종다양성이 풍부하기 때문에 조류 각종의 개체군 추세와 서 식지 적정도를 측정하는데 지표종의 개념으로써 활용되고 있다(Verner et al., 1986). 야생조류 서 식이 가능한 생태계 조성은 단순히 야생조류 서 식의 의미를 떠나 인간 거주공간을 포함한 생태 계 안정을 의미하며 다양한 생물이 공생하며 살 아가는 출발점이 될 수 있다(Kwak, 2010).

우리나라의 도시림은 대부분 인공적으로 조성 된 식재림이고 산림이용 및 인간의 간섭으로 인 하여 중층 및 하층 식생뿐만 아니라 상층부 식생 역시 자연성이 부족한 모습을 보이고 있다(Lee and Lee, 1999; Oh and Park, 2001). 뿐만 아니라 산림의 격리, 녹지의 파편화로 야생동물의 서식 환경이 생물지리학적 섬과 같이 작은 면적으로 세분화 되어 매우 열악한 실정이다(Lee et al., 2010). 따라서 최근 들어 도시 내 공원과 녹지공 간에 대한 관심이 높아지고 있으며 야생동식물의 서식처를 보전하여 녹지 네트워크를 구축하고자 하는 관심도 크게 증가 하고 있다.

따라서 본 연구는 충청남도 당진시에 위치하 는 산림조각을 대상으로 산림의 생태적 다양성과 자연성이 회복될 수 있도록 산림조각의 현존식생 과 야생조류 조사를 통하여 산림식생과 야생조류 출현과의 관계를 분석하고 야생조류 종다양성 증 진을 위한 식생관리방안의 기초자료를 제시하고 자 하였다. 


\section{II. 연구범위 및 방법}

\section{1. 연구지역 현황}

본 연구는 충청남도 당진시의 당진읍, 면천면, 순성면 일원에 위치하는 산림조각 9 개를 대상으 로 하였다. 9 개의 산림조각 가운데 3 곳의 산림조 각은 5 만 $m^{2}$ 미만의 소규모면적, 다른 3 곳은 5 만 $\mathrm{m}^{2}$ 이상 10 만 $\mathrm{m}^{2}$ 미만의 중규모면적, 마지막 3 곳은 10 만m ${ }^{2}$ 이상의 대규모면적으로 구분하여 식생조 사와 야생조류조사를 실시하였다(Figure 1).

당진시의 기후적 특성은 한반도의 기후형인 온대계절풍 및 대륙성 기후권에 속하고 온순한 기후에 해당하여 4계절이 뚜렷하고 겨울철에는 북서계절풍의 영향을 받고 여름에는 남동계절풍 의 영향을 받아 식물구계가 한반도 중부아구(Lee and Yim, 1978)에 속하며 군계수준에서는 냉온 대 중부(Yim and Kira, 1975)에 해당된다. 식생지 리학적 분포는 대륙형으로서 한반도아형의 중부/ 산지형을 이룬다. 바다와 인접한 해안지방은 대 체로 온난하며 겨울에는 해풍의 영향을 많이 받

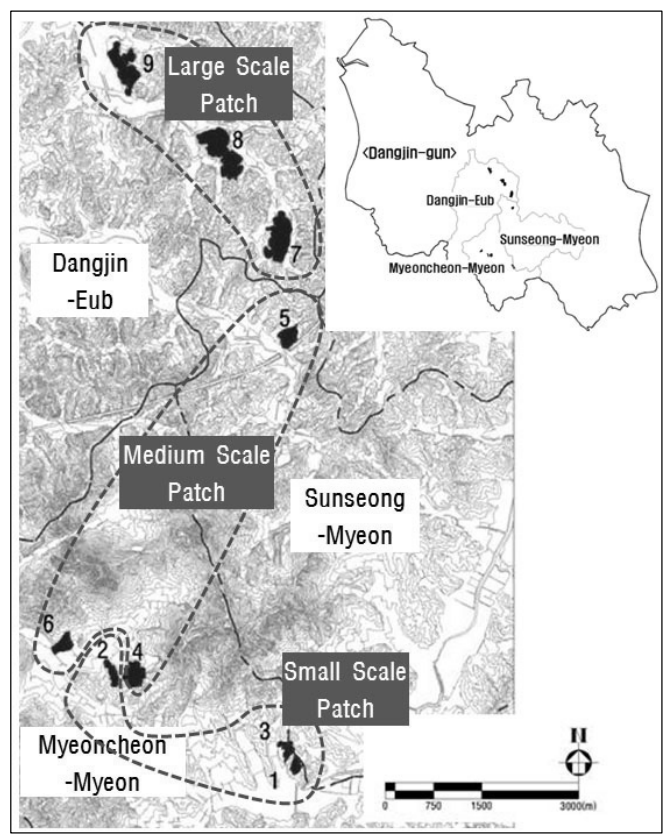

Figure 1. Map of study area including 9 forest patches.
아 북서계절풍이 심하게 불며 체감온도가 몹시 낮다. 여름에는 남동계절풍의 영향을 받아 연평 균기온 $11.4^{\circ} \mathrm{C}$ 내외, 1 월 평균기온 $-3.8^{\circ} \mathrm{C}$ 내외, 8 월 평균기온 $25.6^{\circ} \mathrm{C}$ 내외, 연강수량은 $1,180.6 \mathrm{~mm}$ 이다.

\section{2. 식생조사}

현존식생 조사는 2008년 9월에 실시하였으며 대상지의 산림녹지를 $1 / 5,000$ 수치지형도를 이용 하여 계절성, 잎의 모양, 자연성을 기준으로 하는 상관식생에 의하여 대분류한 후, 층위별 우점종, 종조성, 식생구조를 기준으로 세분류하여 현존식 생을 구분하였고 층위별 식생의 식피율을 조사하 였다. 또한 식물군집 분포현황을 파악하기 위하 여 교목층 수종의 식생의 유형별 면적 및 비율을 산정하였고 산정된 상관층 수목의 우점도에 따라 식생유형을 구분하였다. 그리고 식물종명은 Lee (1980)를 참고하였다.

\section{3. 야생조류조사}

야생조류 조사는 2008 2009년에 걸쳐 9개의 산림조각을 대상으로 여름(2008년 8월), 가을 (2008년 10월), 겨울(2009년 1월), 봄(2009년 5 월)에 각 1 회씩 총 4 회 실시하였다. 계절별로 조 사방법은 대상지의 지정된 등산로나 계곡을 따라 이동하면서 Line transect 방법(Colin et al., 1997) 에 의하여 일출 후부터 정해진 조사경로를 걸어 가며 좌우 $25 \mathrm{~m}$ 에 나타나는 야생조류를 육안 및 쌍안경, 필드 스코프를 이용하여 관찰하고 울음 소리, 날으는 모양 등으로 종과 개체수를 파악하 였다.

조사된 자료는 Lee et al.(2000)를 기준으로 야 생조류 목록을 작성하였고 조류군집의 종구성을 기초로 하여 생물지수를 산정하였다. 생물지수는 각 지역별 지수값을 수치로 나타냄으로서 생물의 서식환경의 양호한 정도를 나타낸다. 본 연구에 서는 종풍부도지수(Margalef, 1958), 균등도지수 (Pielou, 1975), 종다양도지수(Pielou, 1975)를 분 
석하였다.

서식유형은 텃새, 여름철새, 겨울철새, 나그네 새, 길잃은새로 이동성을 구분하였고 길드(guild) 는 유사한 방법으로 동일한 자원을 이용하는 종 의 모임이다(Root, 1967). 본 연구에서는 야생조 류 서식지 다양성을 나타내기 위한 목적으로 이 우신과 Park(1995), $\operatorname{Han}(2000)$ 의 분류기준을 종 합하여 분석하였다. 길드개념은 영소길드(nest guild)와 채이길드(foraging guild)로 나누어지는 데 본 연구에서는 식생유형과의 분석을 위해 야 생조류가 먹이를 구하기 위해 이동하는 특성을 고려하여 채이길드를 위주로 분석하였으며 조류 가 먹이자원을 이용하는 위치에 따라 개활지, 관 목, 수간, 수관, 수간, 수변, 인가로 구분하고 각 공간단위별 길드 유형수를 종합하였다.

\section{III. 결과 및 고찰}

\section{1. 식생현황분석}

각 산림조각의 현존식생 조사 결과(Table 1), 소규모 면적의 산림조각-1은 소나무림(65.03\%) 의 우점으로 조사되었고 산림조각-2는 아까시나 무림(33.13\%)과 상수리나무림(18.44\%)의 우점으 로, 산림조각-3은 소나무림(31.98\%)과 상수리나 무림(26.73\%)의 우점으로 조사되었다. 중규모 면
적의 산림조각-4는 소나무림(60.66\%)이 우점하 는 것으로 조사되었고 산림조각-5는 소나무림 (24.22\%), 밤나무, 상수리나무, 아까시나무 등의 활엽수림이 $52.64 \%$ 로 우점하며 산림조각-6에서 는 소나무림(41.24\%)과 밤나무림(29.39\%), 상수리 나무림(22.0\%)이 우점하는 것으로 조사되었다.

대규모 면적의 산림조각-7은 침엽수림이 $58.58 \%$ 로 우점하고 있으며 산림조각-8에서는 상수리나 무, 밤나무, 아까시나무 등의 활엽수림이 $40.25 \%$ 로 조사되었고 산림조각-9에서는 침엽수림이 $4.33 \%$ 로 밤나무, 상수리나무, 느티나무 등의 활 엽수림이 $20.36 \%$ 로, 혼효림이 $68.15 \%$ 로 조사되 었다. 따라서 조사지역의 현존식생은 패치의 크 기와 식생 우점종에 따라 혼효림형, 활엽수림형, 침엽수림형의 식생유형으로 분류되었다.

\section{2. 야생조류 출현 특성}

각 산림조각에서 출현한 야생조류를 종합한 결 과(Table 2), 산림조각-1에서는 멧비둘기(31.34\%) 가 우점하였고 직박구리(14.94\%), 참새(13.43\%) 가 주요 출현종으로 관찰되었으며 총 12 종 67 개 체가 조사되었다. 산림조각-2에서는 17종 96개체 가 관찰되었고 멧비둘기(21.87\%)가 우점하였고 인가에서 먹이를 찾는 참새(15.63\%)와 붉은머리 오목눈이 $(12.50 \%)$ 가 주요 출현종으로 나타났다.

Table 1. Vegetation types by forest patches scale.

\begin{tabular}{|c|c|c|c|c|c|c|}
\hline \multicolumn{2}{|c|}{ Forest patch } & \multirow{2}{*}{$\operatorname{Area}\left(\mathrm{m}^{2}\right)$} & \multicolumn{3}{|c|}{ Physiognomical vegetation (\%) } & \multirow{2}{*}{ Vegetation type } \\
\hline Scale & Number & & Coniferous forest & Deciduous forest & Mixed forest & \\
\hline \multirow{3}{*}{ Small } & 1 & 29,615 & 65.03 & 26.45 & - & Coniferous forest type \\
\hline & 2 & 41,734 & 28.41 & 51.57 & 16.06 & Deciduous forest type \\
\hline & 3 & 31,389 & 31.98 & 45.15 & 19.27 & Mixed forest type \\
\hline \multirow{3}{*}{ Medium } & 4 & 57,156 & 60.66 & 6.73 & - & Coniferous forest type \\
\hline & 5 & 65,960 & 24.22 & 52.64 & 8.67 & Deciduous forest type \\
\hline & 6 & 94,301 & 41.24 & 51.39 & - & Mixed forest type \\
\hline \multirow{3}{*}{ Large } & 7 & 201,064 & 58.58 & 23.62 & 6.08 & Coniferous forest type \\
\hline & 8 & 266,278 & 36.68 & 40.25 & 19.36 & Deciduous forest type \\
\hline & 9 & 207,359 & 4.33 & 20.36 & 68.15 & Mixed forest type \\
\hline
\end{tabular}


Table 2. The Status on the wild birds of study area.

\begin{tabular}{|c|c|c|c|c|c|c|c|c|c|c|c|c|c|}
\hline \multirow{2}{*}{$\begin{array}{l}\text { Habitat } \\
\text { type }^{*}\end{array}$} & \multirow{2}{*}{ Foraging guild } & \multirow{2}{*}{ Korean name } & \multirow{2}{*}{ Scientific name } & \multicolumn{9}{|c|}{ No. of individual(appearance rate; \%) } & \multirow{2}{*}{ Total } \\
\hline & & & & 1 & 2 & 3 & 4 & 5 & 6 & 7 & 8 & 9 & \\
\hline \multirow{2}{*}{ PM } & \multirow{2}{*}{ Bush } & 꼬까참새 & Emberiza rutila & & $5(5.21)$ & & & & & & & & 5 \\
\hline & & 울새 & Enithacus sibilans & 1( 1.49) & $3(3.13)$ & & & & & & & & 4 \\
\hline \multirow{21}{*}{ Res } & \multirow{2}{*}{ Open terrain } & 말똥가리 & Buteo buteo & & 1( 1.04$)$ & & & & & & & & 1 \\
\hline & & 황조롱이 & Falco tinnunculus & & $1(1.04)$ & & & & & & & & 1 \\
\hline & \multirow{4}{*}{ Bush } & 뀡 & Phasianus colchicus & & & $1(1.54)$ & $1(0.88)$ & $1(2.56)$ & $1(0.96$ & $7(3.32)$ & $1(0.81)$ & & 12 \\
\hline & & 노랑턱멧새 & Emberiza elegans & 1( (1.49) & & $8(12.3)$ & 10( 8.77) & & $3(2.88)$ & $5(2.37)$ & $8(6.45)$ & $20(12.82)$ & 55 \\
\hline & & 딱새 & Phoenicurus auroreus & & $3(3.13)$ & $1(1.54)$ & $3(2.63)$ & $2(5.13)$ & $2(1.92)$ & $5(2.37)$ & $5(4.03)$ & $1(0.64)$ & 22 \\
\hline & & 붉은머리오목눈이 & Paradoxornis webbiana & $7(10.45)$ & $12(12.50)$ & & 20(17.55) & & $2(1.92)$ & $54(25.59)$ & $7(5.64)$ & $8(5.13)$ & 110 \\
\hline & \multirow{3}{*}{ Trunk } & 쇠딱따구리 & Dendrocopos kizuki & & & $1(1.54)$ & $1(0.88)$ & & $2(1.92)$ & $3(1.42)$ & 2( 1.61$)$ & $1(0.64)$ & 10 \\
\hline & & 오색딱따구리 & Dendrocopos major & 1( 1.49) & & $1(1.54)$ & $2(1.75)$ & $1(2.56)$ & $2(1.92)$ & & & $4(2.56)$ & 11 \\
\hline & & 청딱따구리 & Picus canus & 1( 1.49) & $4(4.17)$ & & & 1( 2.56) & $2(1.92)$ & $3(1.42)$ & $4(3.23)$ & $3(1.92)$ & 18 \\
\hline & \multirow{9}{*}{ Canopy } & 동박새 & Zosterops japonica & & & & & & $4(3.85)$ & & & & 4 \\
\hline & & 때까치 & Lanius bucephalus & & 1(1.04) & $1(1.54)$ & & & & & & & 2 \\
\hline & & 멧비둘기 & Streptopelia orientalis & $21(31.34)$ & $21(21.87)$ & $13(20.00)$ & $28(24.56)$ & 6(15.39) & $15(14.42$ & $15(7.11)$ & $9(7.26)$ & $17(10.90)$ & 145 \\
\hline & & 박새 & Parus major & $5(7.46)$ & 1( 1.04) & $8(12.3)$ & 10( 8.77) & $5(12.82)$ & $12(11.54$ & $16(7.58)$ & 13(10.48) & $16(10.26)$ & 86 \\
\hline & & 쇠박새 & Parus palustris & $2(2.99)$ & $2(2.08)$ & $6(9.23)$ & $3(2.63)$ & $1(2.56)$ & $15(14.42)$ & $7(3.32)$ & $18(14.52)$ & $5(3.21)$ & 59 \\
\hline & & 어치 & Garrulus glandarius & & $7(7.29)$ & $1(1.54)$ & & 6(15.39) & & $6(2.84)$ & $2(1.61)$ & $8(5.13)$ & 30 \\
\hline & & 오목눈이 & Aegithalos caudatus & & & $5(7.69)$ & & & $5(4.81)$ & $5(2.37)$ & $8(6.45)$ & $3(1.92)$ & 26 \\
\hline & & 직박구리 & Hypsipetes amaurotis & $10(14.94)$ & $5(5.21)$ & $6(9.23)$ & $15(13.16)$ & 7(17.95) & $5(4.81)$ & $21(9.95)$ & 11( 8.87$)$ & $11(7.05)$ & 91 \\
\hline & & 진박새 & Parus ater & & & & & & $3(2.88)$ & & $4(3.23)$ & $13(8.34)$ & 20 \\
\hline & Water's edge & 물까치 & Cyanopica cyanus & & & & & & & $5(2.37)$ & 6( 4.84) & $10(6.41)$ & 21 \\
\hline & \multirow{2}{*}{ Near house } & 까치 & Pica pica & $8(11.94)$ & $8(8.33)$ & $2(3.08)$ & $8(7.02)$ & $2(5.13)$ & $12(11.54$ & $18(8.53)$ & $7(5.64)$ & $10(6.41)$ & 75 \\
\hline & & 참새 & Passer montanus & $9(13.43)$ & $15(15.63)$ & $5(7.69)$ & & & $3(2.88)$ & $10(4.74)$ & $1(0.81)$ & & 43 \\
\hline \multirow{12}{*}{ SV } & Open terrain & 붉은배새매 & Accipiter soloensis & & & & $1(0.88)$ & & & & & & 1 \\
\hline & \multirow{5}{*}{ Bush } & 숲새 & Urosphena squameiceps & & & & & & & $3(1.42)$ & & & 3 \\
\hline & & 찌르레기 & Sturnus cineraceus & & & & & $2(5.13)$ & & & & & 2 \\
\hline & & 호랑지빠귀 & Turdus dauma & 1(1.49) & & & & $2(5.13)$ & & 2( 0.95$)$ & $1(0.81)$ & $3(1.92)$ & 9 \\
\hline & & 후투티 & Upupa epops & & & & & & & $1(0.47)$ & & & 1 \\
\hline & & 흰배지빠귀 & Turdus pallidus & & & & & & & & $2(1.61)$ & $6(3.85)$ & 8 \\
\hline & \multirow{5}{*}{ Canopy } & 꾀꼬리 & Oriolus chinensis & & $5(5.21)$ & $3(4.62)$ & $9(7.89)$ & & $6(5.77)$ & $4(1.90)$ & $9(7.26)$ & $9(5.77)$ & 45 \\
\hline & & 빼꾸기 & Cuculus canorus & & & & & $1(2.56)$ & & & & $1(0.64)$ & 2 \\
\hline & & 산솔새 & Phylloscopus coronatus & & & & & & & & $1(0.81)$ & $1(0.64)$ & 2 \\
\hline & & 큰유리새 & Cyanoptila cyanomelana & & & & & & & $4(1.90)$ & & & 4 \\
\hline & & 파랑새 & Eurystomus orientalis & & $2(2.08)$ & & $1(0.88)$ & & $3(2.88)$ & $2(0.95)$ & & $3(1.92)$ & 11 \\
\hline & Near house & 제비 & Hirundo rustica & & & & & & & $3(1.42)$ & & & 3 \\
\hline WV & Canopy & 상모솔새 & Regulus regulus & & & $3(4.62)$ & $2(1.75)$ & $2(5.13)$ & $7(6.73)$ & $12(5.69)$ & $5(4.03)$ & $3(1.92)$ & 34 \\
\hline \multicolumn{4}{|c|}{ Total } & 67 & 96 & 65 & 114 & 39 & 104 & 211 & 124 & 156 & 976 \\
\hline
\end{tabular}

* Habitat type : Resident bird(Res), Summer visitor(SV), Winter visitor(WV), Passage migrant bird(PM). 
또한 개활지에서 채이길드를 형성하는 맹금류 황 조롱이와 말똥가리가 관찰되었다. 산림조각- 3 은 16 종 65 개체가 관찰되었으며 수목의 가지에서 서식하는 멧비둘기 $(20.00 \%)$ 가 우점하였고 노랑 턱멧새(12.30\%), 박새(12.30\%)가 주요 출현종으 로 나타났다. 산림조각-4에서는 멧비둘기(24.56\%) 가 우점하였고 관목덤블에서 주로 서식하는 붉은 머리오목눈이(17.55\%)와 직박구리(13.16\%)가 주 로 출현 하였으며 총 15 종 114 개체가 관찰되었 다. 산림조각-5에서는 직박구리(17.95\%)가 우점 하였고 어치(15.39\%)와 멧비둘기(15.39\%)가 출 현하였고 총 14 종 39 개체가 관찰되었다. 산림조 각-6은 19종 104 개체가 관찰되었으며 멧비둘기 (14.42\%)와 쇠박새(14.42\%)가 우점하였고 주요 출현종으로 박새(11.54\%)와 까치(11.54\%)가 관 찰되었다. 또한 산림의 내부에서 주로 서식하는 딱따구리류가 청딱따구리, 오색딱따구리, 쇠딱따 구리가 각 2 개체씩 관찰되었다. 산림조각-7에서 는 총 23종 211개체가 관찰되었으며 붉은머리오 목눈이 $(25.59 \%)$ 가 우점종으로 나타났고 인가에 서 채이길드를 형성하는 까치(8.53\%)와 수관에 서 먹이를 찾는 박새(7.58\%)가 주요 출현종으로 나타났다. 또한 여름철새인 꾀꼬리(1.90\%), 큰유 리새 $(1.90 \%)$ 와 후투티 1 개체가 조사되었으며 겨 울철새인 상모솔새(5.69\%)도 관찰되었다. 청딱 따구리와 같은 딱따구리류는 안정된 산림내부에 서 서식하는 종으로(Won, 1981) 가을과 여름에
관찰 되어져 산림조각-7의 산림 내부종임을 확인 할 수 있었다. 산림조각-8은 총 21종 124개체가 관찰되었으며 그 중 쇠박새(14.52\%)가 우점하였 고 박새(10.48\%)와 직박구리(8.87\%)가 주로 출 현하였으며 여름 철새인 꾀꼬리가 9 개체 관찰되 었다. 산림조각-9에서는 총 22 종 156 개체가 관찰 되었고 텃새이면서 관목에서 주로 서식하는 노랑 턱멧새( $12.82 \%)$ 의 출현빈도가 가장 높게 나타났 다. 또한 멧비둘기(10.90\%)와 박새(10.26\%)의 출 현빈도도 높았으며 여름철새인 파랑새도 2 개체 출현하였다.

\section{3. 서식유형 및 채이길드 분석}

서식유형은 $\operatorname{Res}$ (텃새), $\mathrm{SV}$ (여름철새), $\mathrm{WV}$ (겨 울철새), $\mathrm{PM}$ (나그네새)로 이동성을 구분하였고 총 출현종 36 종 976 개체 중 텃새는 21 종 842 개체 로 가장 많았으며 다음으로 여름철새가 12 종 90 개체, 나그네새 2 종 9 개체, 겨울철새 1 종 34 개체 순으로 나타났다.

산림조각의 규모에 따른 야생조류의 서식유형 별 출현현황을 보면 텃새와 겨울철새의 경우 소 규모 산림조각에서 보다 대규모 산림조각으로 갈 수록 종수는 큰 변화 없이 개체수만 증가한 반면 에 여름 철새의 경우 소규모 산림조각에서 대규 모 산림조각으로 갈수록 종과 개체수 모두 증가 하는 것을 알 수 있었다(Table 3).

한편, 식생유형에 따른 야생조류 서식유형을

Table 3. Habitat types of wild birds by forest patches scale.

\begin{tabular}{c|c|c|c|c|c|c}
\hline \hline \multirow{2}{*}{ Habitat type* } & \multicolumn{2}{|c|}{ Small scale } & \multicolumn{2}{c|}{ Medium scale } & \multicolumn{2}{c}{ Large scale } \\
\cline { 2 - 7 } & $\begin{array}{c}\text { No. of } \\
\text { species } \\
\text { (rate; \%) }\end{array}$ & $\begin{array}{c}\text { No. of } \\
\text { individual } \\
\text { (rate; \%) }\end{array}$ & $\begin{array}{c}\text { No. of } \\
\text { species } \\
\text { (rate; \%) }\end{array}$ & $\begin{array}{c}\text { No. of } \\
\text { individual } \\
\text { (rate; \%) }\end{array}$ & $\begin{array}{c}\text { No. of } \\
\text { species } \\
\text { (rate; \%) }\end{array}$ & $\begin{array}{c}\text { No. of } \\
\text { individual } \\
\text { (rate; \%) }\end{array}$ \\
\hline PM & $2(8.3)$ & $9(4.0)$ & - & - & - & - \\
\hline Res & $18(75.0)$ & $205(89.9)$ & $17(70.8)$ & $221(86.0)$ & $17(60.7)$ & $416(84.9)$ \\
\hline SV & $3(12.5)$ & $11(4.8)$ & $6(25.0)$ & $25(9.7)$ & $10(35.7)$ & $54(11.0)$ \\
\hline WV & $1(4.2)$ & $3(1.3)$ & $1(4.2)$ & $11(4.3)$ & $1(3.6)$ & $20(4.1)$ \\
\hline Total & $24(100.0)$ & $228(100.0)$ & $24(100.0)$ & $257(100.0)$ & $28(100.0)$ & $490(100.0)$ \\
\hline
\end{tabular}

* Habitat type : Resident bird(Res), Summer visitor(SV), Winter visitor(WV), Passage migrant bird(PM). 
Table 4. Habitat types of wild birds by vegetation types of forest patches.

\begin{tabular}{c|c|c|c|c|c|c}
\hline \multirow{2}{*}{ Habitat type* $^{*}$} & \multicolumn{2}{|c|}{ Coniferous forest type } & \multicolumn{2}{c|}{ Deciduous forest type } & \multicolumn{2}{c}{ Mixed forest type } \\
\cline { 2 - 7 } & $\begin{array}{c}\text { No. of } \\
\text { species } \\
\text { (rate; \%) }\end{array}$ & $\begin{array}{c}\text { No. of } \\
\text { individual } \\
\text { (rate; \%) }\end{array}$ & $\begin{array}{c}\text { No. of } \\
\text { species } \\
\text { (rate; \%) }\end{array}$ & $\begin{array}{c}\text { No. of } \\
\text { individual } \\
\text { (rate; \%) }\end{array}$ & $\begin{array}{c}\text { No. of } \\
\text { species } \\
\text { (rate; \%) }\end{array}$ & $\begin{array}{c}\text { No. of } \\
\text { individual } \\
\text { (rate; \%) }\end{array}$ \\
\hline PM & $1(3.8)$ & $1(0.2)$ & $2(6.9)$ & $8(3.1)$ & - & - \\
\hline Res & $16(61.6)$ & $346(88.3)$ & $19(65.5)$ & $219(84.9)$ & $20(74.1)$ & $277(85.2)$ \\
\hline SV & $8(30.8)$ & $31(7.9)$ & $7(24.1)$ & $24(9.3)$ & $6(22.2)$ & $35(10.8)$ \\
\hline WV & $1(3.8)$ & $14(3.6)$ & $1(3.5)$ & $7(2.7)$ & $1(3.7)$ & $13(4.0)$ \\
\hline Total & $26(100.0)$ & $392(100.0)$ & $29(100.0)$ & $258(100.0)$ & $27(100.0)$ & $325(100.0)$ \\
\hline
\end{tabular}

* Habitat type : Resident bird(Res), Summer visitor(SV), Winter visitor(WV), Passage migrant bird(PM).

Table 5. Foraging guild of wild birds by forest patches scale.

\begin{tabular}{c|c|c|c|c|c|c}
\hline \hline \multirow{2}{*}{ Foraging guild* } & \multicolumn{2}{|c|}{ Small scale } & \multicolumn{2}{c|}{ Medium scale } & \multicolumn{2}{c}{ Large scale } \\
\cline { 2 - 7 } & $\begin{array}{c}\text { No. of } \\
\text { species } \\
\text { (rate; } \%)\end{array}$ & $\begin{array}{c}\text { No. of } \\
\text { individual } \\
\text { (rate; \%) }\end{array}$ & $\begin{array}{c}\text { No. of } \\
\text { species } \\
\text { (rate; \%) }\end{array}$ & $\begin{array}{c}\text { No. of } \\
\text { individual } \\
\text { (rate; \%) }\end{array}$ & $\begin{array}{c}\text { No. of } \\
\text { species } \\
\text { (rate; \%) }\end{array}$ & $\begin{array}{c}\text { No. of } \\
\text { individual } \\
\text { (rate; \%) }\end{array}$ \\
\hline Open terrain & $2(8.3)$ & $2(0.9)$ & $1(4.2)$ & $1(0.4)$ & - & - \\
\hline Bush & $7(29.2)$ & $43(18.9)$ & $6(25.0)$ & $49(19.1)$ & $8(28.6)$ & $138(28.1)$ \\
\hline Trunk & $3(12.5)$ & $8(3.5)$ & $3(12.5)$ & $11(4.3)$ & $3(10.7)$ & $20(4.1)$ \\
\hline Canopy & $10(41.7)$ & $128(56.1)$ & $12(50.0)$ & $171(66.5)$ & $13(46.4)$ & $262(53.5)$ \\
\hline Water's edge & - & - & - & - & $1(3.6)$ & $21(4.3)$ \\
\hline Near house & $2(8.3)$ & $47(20.6)$ & $2(8.3)$ & $25(9.7)$ & $3(10.7)$ & $49(10.0)$ \\
\hline Total & $24(100.0)$ & $228(100.0)$ & $24(100.0)$ & $257(100.0)$ & $28(100.0)$ & $490(100.0)$ \\
\hline
\end{tabular}

보면 나그네새, 여름철새, 겨울철새의 종수는 식 생유형과는 상관관계가 없는 반면에 텃새는 침엽 수림형 보다 혼효림형에서 종수가 증가하는 경향 을 보였다(Table 4).

채이길드에 따른 종수와 개체수를 살펴보면, 수관채이종이 15 종 561개체로 가장 많았으며 다 음으로 관목채이종 11 종 230 개체, 수간채이종 3 종 39 개체, 맹금류 3 종 3 개체, 수변채이종 1 종 21 개체 순이었다.

산림조각의 규모에 따른 야생조류의 채이길드 별 출현현황은 산림조각의 규모가 커질수록 수관 과 관목에서 채이길드를 형성하는 야생조류의 종 수 및 개체수가 증가하는 것을 알 수 있었고 (Table 5) 산림조각의 식생유형에 따른 야생조류 의 채이길드를 보면 수관에서 채이길드를 형성하
는 야생조류의 종수가 침엽수림형보다 혼효림형 에서 증가하는 경향을 보였으며 관목, 수간, 인가 등의 채이길드를 형성하는 종들에게는 식생유형 에 따른 변화는 보이지 않았다(Table 6).

\section{4. 식생유형과 조류 종다양성 분석}

산림조각별 야생조류의 생물지수를 분석한 결 과, 산림조각의 크기와 함께 식생유형에 따라 종 풍부도지수, 균등도지수, 종다양도지수의 차이가 나타났다.

특히, 종풍부도와 개체수의 상대적인 균형성을 의미하고 군집의 복잡성을 나타내는 종다양도지 수의 경우, 소규모 산림조각(1.1281)과 침엽수림 형(1.1328)의 식생유형에서 가장 낮았고 대규모 산림조각(1.2694)과 혼효림(1.2864)의 식생유형 
Table 6. Foraging guild of wild birds by vegetation types of forest patches.

\begin{tabular}{c|c|c|c|c|c|c}
\hline \hline \multirow{2}{*}{ Foraging guild* } & \multicolumn{2}{|c|}{ Coniferous forest type } & \multicolumn{2}{c|}{ Deciduous forest type } & \multicolumn{2}{c}{ Mixed forest type } \\
\cline { 2 - 7 } & $\begin{array}{c}\text { No. of } \\
\text { species } \\
\text { (rate; \%) }\end{array}$ & $\begin{array}{c}\text { No. of } \\
\text { individual } \\
\text { (rate; \%) }\end{array}$ & $\begin{array}{c}\text { No. of } \\
\text { species } \\
\text { (rate; \%) }\end{array}$ & $\begin{array}{c}\text { No. of } \\
\text { individual } \\
\text { (rate; \%) }\end{array}$ & $\begin{array}{c}\text { No. of } \\
\text { species } \\
\text { (rate; \%) }\end{array}$ & $\begin{array}{c}\text { No. of } \\
\text { individual } \\
\text { (rate; \%) }\end{array}$ \\
\hline Open terrain & $1(3.8)$ & $1(0.2)$ & $2(6.7)$ & $2(0.8)$ & - & - \\
\hline Bush & $8(30.8)$ & $121(30.9)$ & $9(30.0)$ & $53(20.5)$ & $6(23.1)$ & $56(17.2)$ \\
\hline Trunk & $3(11.6)$ & $11(2.8)$ & $3(10.0)$ & $12(4.7)$ & $3(11.6)$ & $16(4.9)$ \\
\hline Canopy & $10(38.5)$ & $198(50.5)$ & $13(43.3)$ & $152(58.9)$ & $14(53.8)$ & $211(64.9)$ \\
\hline Water's edge & $1(3.8)$ & $5(1.3)$ & $1(3.3)$ & $6(2.3)$ & $1(3.8)$ & $10(3.1)$ \\
\hline Near house & $3(11.5)$ & $56(14.3)$ & $2(6.7)$ & $33(12.8)$ & $2(7.7)$ & $32(9.9)$ \\
\hline Total & $26(100.0)$ & $392(100.0)$ & $30(100.0)$ & $258(100.0)$ & $26(100.0)$ & $325(100.0)$ \\
\hline
\end{tabular}

Table 7. Community Indices of forest patches by different size.

\begin{tabular}{c|c|c|c|c|c}
\hline \hline Forest patch & $\begin{array}{c}\text { No. of } \\
\text { species }\end{array}$ & $\begin{array}{c}\text { No. of } \\
\text { individual }\end{array}$ & Richness index & Evenness index & Diversity index \\
\hline Small scale & 24 & 228 & 4.2362 & 0.3550 & 1.1281 \\
\hline Medium scale & 24 & 257 & 4.1448 & 0.3692 & 1.1733 \\
\hline Large scale & 28 & 490 & 4.2362 & 0.3810 & 1.2694 \\
\hline
\end{tabular}

Table 8. Community Indices of forest patches by vegetation types.

\begin{tabular}{c|c|c|c|c|c}
\hline \hline Vegetation type & $\begin{array}{c}\text { No. of } \\
\text { species }\end{array}$ & $\begin{array}{c}\text { No. of } \\
\text { individual }\end{array}$ & Richness index & Evenness index & Diversity index \\
\hline Coniferous forest type & 26 & 392 & 4.1867 & 0.3477 & 1.1328 \\
\hline Deciduous forest type & 30 & 258 & 5.2224 & 0.3761 & 1.2793 \\
\hline Mixed forest type & 26 & 318 & 4.3387 & 0.3948 & 1.2864 \\
\hline
\end{tabular}

에서 가장 높게 나타났다(Table 7, Table 8). 다시 말해 소규모 산림조각에서 보다 대규모 산림조각 에서, 침엽수림형의 산림조각에서 보다 혼효림형 의 산림조각에서 조류군집이 단순하지 않고 복잡 해지는 것을 알 수 있었으며 이는 산림의 크기와 다양한 수목으로 이루어진 복잡한 군집구조가 야 생조류의 서식에 영향을 미친다는 것을 반증하는 것으로 생각되었다.

\section{IV. 결 론}

본 연구에서는 산림성 야생조류의 종다양성 증진을 위한 식생관리방안 마련시 기초자료를 제
시하고자 당진시의 9 개의 산림조각을 대상으로 산림식생과 야생조류 출현과의 상관성를 분석하 였다.

그 결과, 야생조류 출현 특성으로 산림조각의 면적이 대규모이면서 낙엽활엽수와 상록침엽수 가 혼생하는 혼효림의 식생유형에서 종수 및 개 체수의 출현빈도가 높게 나타났다. 반면, 상대적 으로 식생면적이 소규모이면서 상록침엽수가 우 점하는 산림에서는 야생조류의 종수와 개체수가 적게 나타났다.

또한 산림조각의 면적이 클수록 야생조류의 종다양도지수가 높게 나타났으며 이는 여름 철새 의 출현빈도와 상관관계가 있었다. 식생유형의 
경우, 혼효림형에서 종다양도지수가 높게 나타났 으며 텃새의 종수에 의해 영향을 받는 것으로 확 인되었다.

따라서 여름철새와 텃새의 출현은 산림조각의 크기와 식생유형의 영향을 가장 많이 받는 것으 로 나타났다. 여름철새의 서식지환경을 보호하기 위해서는 대규모의 산림이 소규모의 산림조각으 로 세분화되지 않고 일정 규모 이상의 산림면적 이 유지될 수 있도록 관리할 필요성이 있으며 소 규모의 산림조각 주변으로는 생태통로의 역할을 할 수 있는 징검다리 녹지를 두어 여름철새의 이 동을 유도해야 할 것으로 생각되었다.

채이길드의 경우, 산림조각의 규모가 클수록 관목과 수관에 서식하는 야생조류의 종수와 개체 수가 증가하였고 수관과 관목에서 먹이를 찾는 야생조류가 서식지환경에 가장 큰 영향을 받는 것으로 분석되었다. 즉 다양한 채이길드를 가진 야생조류의 서식기반을 위해서는 다양한 층위에 서 먹이를 구할 수 있도록 산림 수목의 수관층, 수간층, 관목층 등의 식생구조와 높은 식피율을 가진 다층구조의 산림식생을 유지 할 수 있도록 관리해야 할 것이며 이는 산림 내 야생조류의 종 다양성을 높일 수 있을 것으로 생각되었다.

\section{인 용 문 헌}

Choi, J. W. 2004. (A) Study on the enhancement methods for the wildbird migration and the habitat structure in green corridor. MS dissertation, University of Seoul, Seoul. (in Korean with English summary)

Colin, J. B., N. D. Burgess and D. A. Hill. 1997. Bird census techniques. Academic press limited (4th), London, pp. 257.

Han, B. H. 2000. Ecological assessment and planting models of green linkage for ecocity realization. Ph.D dissertation, University of Seoul, Seoul.
Jang, G. S. 2008. A preliminary study on the adjustment of forest-based wildlife protection area. Journal of the Korean Institute of Landscape Architecture 36(1):62-69. (in Korean with English summary)

Kwak, J. I. 2007. Improvement plan of the landuse structure and the green structure for establishment of the wildbirds' habitation base in urban area - A case study of Gangdong-gu in Seoul -. MS dissertation, University of Seoul, Seoul. (in Korean with English summary)

Lee, C. B. 1980. Illustrated flora of Korea. Hyangmoonsa, Seoul. pp. 990. (in Korean)

Lee, D. P. and K. W. Lee. 1999. Community structure of birds at the urban forest in Kwangju metropolitan city. Collection of dissertations of Honam University $20: 551$ 562. (in Korean with English summary)

Lee, K. J., K. W. Kim, K. S. Ki and J. H. Yeum. 2010. A study on charateristics of birds habitat in urban forest, Seoul metropolitan city. Pro. Kor. Soc. Env. Eco. Con. 20(2) : 77-80. (in Korean with English summary)

Lee, W. S., T. H. Koo, J. Y. Park and T. Taniguchi. 2000. A field guide to the birds of korea. LG evergreen foundation, Seoul. (in Korean)

Lee, W. T. and Y. J. Yim. 1978. Studies on the distribution of vascular plant in the Korean Peninsula. Jour. Kor. Pl. Tax. 8 (Appendix) : 1-33. (in Korean with English summary)

Margalef, D. R. 1958. Information theory in ecology. Gen. Syst. $3: 36-71$.

National Research Council. 1986. Ecological knowledge and environmental problem-solving. National academy press, Washington D.C. 
Oh, K. K. and S. G. Park. 2001. Edge vegetation structure of trail in Kyeryongsan national park, Korea. Kor. J. Env. Eco. 14(4) : 280286. (in Korean with English summary)

Park, C. Y. 1994. Establishment and management of urban forests for the inhabitation of wild birds. MS dissertation, Seoul National University, Seoul. (in Korean with English summary)

Pieloue, C. 1975. Ecological diversity. New York, John Wiley and Sons.

Root, R. B. 1967. The niche exploitation pattern of the blue-gray gnatcather. Ecol. monogr. $37: 317-350$.
Shaw, J. H. 1985. Introduction to wildlife management. McGraw-Hill Book Campany, pp. 316.

Verner, J., M. L. Morison and C. J. Ralph. 1986. Wildlife 2000; Modeling habitat relationships of terrestrial vertebrates. University of Wisconsin press, Madison Wisconsin.

Won, P. O. 1981. Illustrated flora and fauna of Korea vol. 25 avifauna. Education department. pp. 1126.

Yim, Y. J. and T. Kira. 1975, Distribution of forest vegetation and climate in the Korean Peninsula I. Distribution of some indices of thermal climate. Jap. J. Ecol. $25: 77-88$. 